\title{
Physical Activity and Metabolic Health in New Zealand European and Pacific Women from the Promise Study ${ }^{\dagger}$
}

\author{
Jo Slater 1, Rozanne Kruger ${ }^{1,}$ Nikki Renall 1,2, Marilize Richter ${ }^{1}$, Marine Corbin ${ }^{3}$, \\ Wendy J. O'Brien ${ }^{1}$, Leigh Signal ${ }^{4}$ and Bernhard H. Breier ${ }^{1,2}$ \\ 1 School of Sport, Exercise and Nutrition, College of Health, Massey University, Auckland 0632, \\ New Zealand; j.s.slater@massey.ac.nz (J.S.); r.kruger@massey.ac.nz (R.K.); n.renall@massey.ac.nz (N.R.); \\ m.richter@massey.ac.nz (M.R.); w.j.obrien@massey.ac.nz (W.J.O.) \\ 2 Riddet Institute, Centre of Research Excellence, Massey University, Palmerston North 4474, New Zealand; \\ n.renall@massey.ac.nz (N.R.); b.breier@massey.ac.nz (B.B.H.) \\ 3 Centre for Public Health Research (CPHR), College of Health, Massey University, Wellington 6021, \\ New Zealand; m.corbin@massey.ac.nz \\ 4 Sleep/Wake Research Centre, College of Health, Massey University, Wellington 6021, New Zealand; \\ t.l.signal@massey.ac.nz \\ * Correspondence: b.breier@massey.ac.nz; Tel: +64-9-414-0800 (ext. 43652) \\ + Presented at the 2018 Nutrition Society of New Zealand Annual Conference, Auckland, New Zealand, \\ 28-30 November 2018.
}

Published: 12 March 2019

Background: This study investigates relationships between physical activity (PA) and biomarkers of metabolic health in populations with different metabolic disease risk; Pacific and New Zealand European (NZE) women with different body composition profiles.

Methods: Pacific $(36 \%)$ and NZE $(64 \%)$ women $(n=236)$ aged $18-45$ years were recruited and classified as either low- $\left(18.5-25.0 \mathrm{~kg} \cdot \mathrm{m}^{-2}\right)$ or high-BMI $\left(\geq 30.0 \mathrm{~kg} \cdot \mathrm{m}^{-2}\right)$. PA was assessed from hip-mounted accelerometers worn for seven-consecutive days. BMI was calculated from measured height and weight. Dietary intake was assessed from 5-day food records. Fasting blood samples were taken to measure biomarkers of metabolic health.

Results: Across all participants the majority of accelerometer-wearing time was spent in sedentary behaviour $(40 \%)$ or sleeping $(34 \%)$, whilst time spent in light PA was $23 \%$ and in moderate-to-vigorous PA (MVPA) was $2 \%$. Significant differences in MVPA were found between BMI $(p \leq 0.05)$ and ethnic $(p \leq 0.001)$ groups (min $\cdot$ day $\left.^{-1}\right)$ : Pacific, high-BMI (19.1) and low-BMI (20.6); NZE, high-BMI (30.1) and low-BMI (38.3). Dietary intake and BMI were not associated with time spent in PA. Highly significant differences in insulin were found between BMI $(p \leq 0.001)$ and ethnic $(p \leq 0.001)$ groups (uU.ml-1): Pacific, high-BMI (28.0) and low-BMI (12.1); NZE, high-BMI (15.0) and low-BMI (7.7); whilst plasma glucose differed only between BMI groups $\left(p \leq 0.001 ; \mathrm{mmol} \cdot \mathrm{L}^{-1}\right)$ : Pacific, high-BMI (5.6) and low-BMI (5.3); NZE, high-BMI (5.5) and low-BMI (5.1). For every percent increase in MVPA time, insulin decreased $(p \leq 0.05)$ in Pacific $(7 \%)$ and NZE $(12 \%)$ women. In NZE women, for every percent increase in MVPA time, an equivalent decrease in fasting glucose was observed $(p \leq 0.05)$.

Conclusions: Fasting insulin differed markedly between ethnic and BMI groups, with increased risk of hyperinsulinemia in Pacific and high-BMI women. Associations for insulin were most sensitive to MVPA. Further analyses will explore which specific pathways may explain increased metabolic disease risk in women of different ethnic and body composition groups.

(C) 2019 by the authors. Licensee MDPI, Basel, Switzerland. This article is an open access article distributed under the terms and conditions of the Creative Commons Attribution (CC BY) license (http://creativecommons.org/licenses/by/4.0/). 